\title{
Compaction simulation of nano-crystalline metals with molecular dynamics analysis
}

\author{
A.R. Khoei ${ }^{\text {a }}$, A. Rezaei Sameti, H. Mofatteh and M. Babaei \\ Center of Excellence in Structures and Earthquake Engineering, Department of Civil Engineering, Sharif University of Technology, \\ P.O. Box. 11365-9313, Tehran, Iran
}

\begin{abstract}
The molecular-dynamics analysis is presented for 3D compaction simulation of nano-crystalline metals under uniaxial compaction process. The nano-crystalline metals consist of nickel and aluminum nano-particles, which are mixed with specified proportions. The EAM pair-potential is employed to model the formation of nano-particles at different temperatures, number of nano-particles, and mixing ratio of $\mathrm{Ni}$ and $\mathrm{Al}$ nano-particles to form the component into the shape of a die. The die-walls are modeled using the Lennard-Jones inter-atomic potential between the atoms of nano-particles and die-walls. The forming process is model in uniaxial compression, which is simulated until the full-dense condition is attained at constant temperature. Numerical simulations are performed by presenting the densification of nano-particles at different deformations and distribution of dislocations. Finally, the evolutions of relative density with the pressure as well as the stress-strain curves are depicted during the compaction process.
\end{abstract}

\section{Introduction}

Powder metallurgy is assumed as a method of producing the near-to-net shape industrial components from the loose powders by executing the pressure with or without applying the heat. In this process, the densification of powder is in accordance with the structural features, e.g. the hardness, plastic behavior, and surface characteristics, and the geometrical features of powder, e.g. the particle size, shape, and distribution [1]. A remarkable privilege of this method is the facility in mixing various types of powder materials to obtain the required characteristics [2]. This capability of powder metallurgy enables one to fabricate the products with variant mechanical features.

In compaction simulation of metal powders, the size of particles dramatically affects the densification process and varies from the nano- to micro-scales. Basically, the discrete (micro) and continuum (macro) techniques are developed to model the powder compaction process [3-8]. In discrete (micro) techniques, there have been taken several simplifying assumptions into the computation to alleviate the problem complexity and computational cost [3-5]. However in the continuum (macro) models, the use of appropriate plasticity models have been a great interest in modeling the micro-powder forming [6-8]. In nanoscale particles, the ratio of surface atoms to volume atoms is significantly considerable in comparison to the micro or macro-particles [9]. Thus, it can be expected that the behavior of nano-scale particles in compaction process can differ noticeably from the behavior of micro-scale particles that highlight the necessity of simulating the nano-particles compaction individually.
There are several numerical simulations reported in literature for modeling of the nano-powder compaction. Boltachev et al. [10] employed the granular dynamics method to simulate the quasi-static uniaxial compaction of nano-powders. They investigated the efficiency of particles size in the quasi-static compaction of nanopowders using the granular dynamic method [11]. Suryanarayanan and Sastry [12] developed a theoretical model on the basis of a micro-mechanism model to simulate the densification of nano-particles under uniaxial and hydrostatic pressing. Balakrishnan et al. [13] simulated the consolidation of nano-particles by applying the discrete element method (DEM).

One of the most popular techniques proposed by researches to study the behavior of nano-particles is based on the molecular dynamics (MD) method [14-19]. In this regard, Henz et al. [14] performed the MD analysis to verify the energetic reaction of the nickel and aluminum nano-particles. In their study, two distinct models were considered for $\mathrm{Ni}$ and $\mathrm{Al}$ nano-particles, including the separated nano-particles and coated nanoparticles. Zhang et al. [16] investigated the behavior of copper nano-particles in the die-compaction process by applying the MD method. They studied the compaction behavior for various particle sizes, temperatures, and packing arrangements, and deduced that these parameters can affect the mechanical properties of the compacted components. Stone et al. [17] determined the coefficients of inter-particle friction under the uniaxial compression by applying the MD technique. Kiselev $[\mathbf{1 8}, \mathbf{1 9}]$ simulated the exertion of external force on the spherical piston comprised of copper and copper-molybdenum mixture

\footnotetext{
${ }^{\mathrm{a}}$ Corresponding author: arkhoei@ sharif.edu
} 
nano-particles with MD analysis. They indicated that because of the surface traction, the copper nano-particles fill the voids and the crystalline structures change into amorphous forms under a small movement of the piston.

Considering the extremely nonlinear behavior of nano-particles through the process of compaction, it is required to implement a powerful technique in compaction simulation of nano-crystalline metals. In this study, the molecular dynamics technique is employed to study the forming process of nano-particles under diepressing. The nano-crystalline metals consist of nickel and aluminum nano-particles. The simulation of forming process is accomplished by imposing the uniaxial compression on a set of nano-particles at the constant temperature. In order to study the densification behavior of combined Ni/Al nano-particles, numerical simulations are performed for various mixing ratios of $\mathrm{Ni}$ and $\mathrm{Al}$ nano-particles. Moreover, the effect of temperature and number of nano-particles are investigated through the compaction process. The plan of the paper is as follows; in Section 2, the methodology and desired numerical simulations are described. The geometrical characteristics of specimens together with the inter-atomic potential and the procedure of modeling are described in this section. In Section 3, the results of computational modeling are presented by illustrating the evolutions of stress versus strain and the relative density versus pressure for various parameters of forming process.

\section{Methodology}

The compaction simulation of metal nano-particles is performed using three-dimensional uniaxial compression on a set of metallic powders consisting of nickel and aluminum nano-particles with various mixing ratios. In order to investigate the influence of the number of nanoparticles, three types of nano-particles arrangement, including 4, 16 and 64 nano-particles, are considered. To simulate the formation of nano-particles, the die-walls are positioned as the rectangular prism with the interior dimensions of $10.7 \times 10.7 \times 5.5 \mathrm{~nm}^{3}, 21.1 \times 21.1 \times 5.5 \mathrm{~nm}^{3}$ and $41.9 \times 41.9 \times 5.5 \mathrm{~nm}^{3}$ corresponding to 4,16 and 64 nanoparticles, respectively. In view of crystallography, the metallic atoms are arranged initially as the F.C.C structure with the lattice constants of $0.352 \mathrm{~nm}$ for nickel and $0.405 \mathrm{~nm}$ for aluminum nano-particles, respectively. Each nano-particle is considered as a spherical shape with the diameter of $5 \mathrm{~nm}$ that contains about 4000 atoms of aluminum and 6000 atoms of nickel. In order to investigate the performance of various mixing ratios in die-forming process, the nano-particles are combined with five distinct ratios of $\mathrm{Ni}$ and $\mathrm{Al}$ as follows; (1) pure $\mathrm{Ni}$ nano-particles, (2) pure Al nano-particles, (3) mixed $25 \% \mathrm{Ni}-75 \% \mathrm{Al}$, (4) mixed $50 \% \mathrm{Ni}-50 \% \mathrm{Al}$, (5) mixed $75 \% \mathrm{Ni}-25 \% \mathrm{Al}$, in which for all mixed $\mathrm{Ni}-\mathrm{Al}$, the positions of nano-particle are chosen randomly. The initial configurations of components with 4, 16 and 64 nano-particles for the mixed $50 \% \mathrm{Ni}-50 \% \mathrm{Al}$ are shown in Figure 1. The nano-particles are set at the distance of $0.2 \mathrm{~nm}$ from each other, and $0.25 \mathrm{~nm}$ from the die-walls. (a)

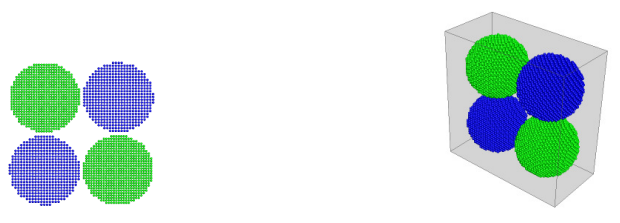

(b)
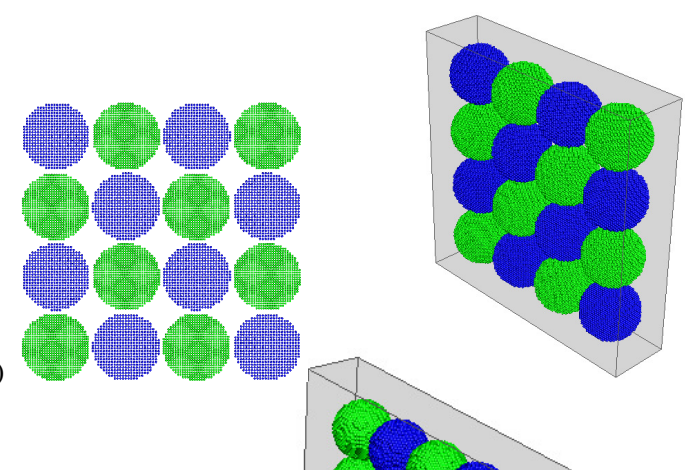

(c)

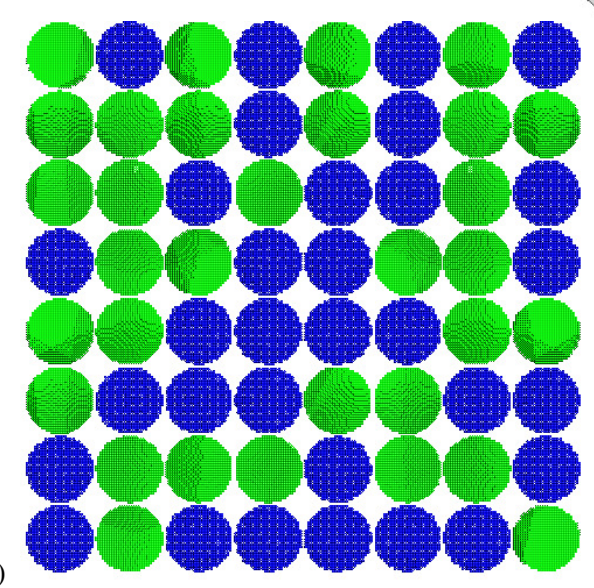

Figure 1. The initial configurations of $\mathrm{Al}$ and $\mathrm{Ni}$ nano-particles for the mixed $50 \% \mathrm{Al}-50 \% \mathrm{Ni}$ with (a) 4, (b) 16 and, (c) 64 nano-particles (the blue atoms corresponds to $\mathrm{Al}$ and green atoms corresponds to $\mathrm{Ni}$ ).

It has been shown that the inter-atomic potential of the embedded-atom method (EAM) can be applied efficiently in molecular dynamics analysis of $\mathrm{Ni}, \mathrm{Al}$ and mixed $\mathrm{Ni}-$ $\mathrm{Al}$ atoms with sufficient accuracy $[15,20,21]$. Due to versatility and accuracy of the EAM inter-atomic potential in modeling of large atomic systems, Henz et al. 
[15] studied the sintering of $\mathrm{Ni}$ and $\mathrm{Al}$ nano-particles using the EAM potential. Olmsted et al. [20] employed the EAM potential to investigate the velocity of edge and screw dislocations in the $\mathrm{Al}$ and Ni materials. Zhang et al. [21] simulated the $\mathrm{Ni}-\mathrm{Al}$ interface diffusion using the EAM potential. In the current study, the inter-atomic interaction is defined based on the EAM potential, which is basically expressed as $[\mathbf{2 2}, \mathbf{2 3}]$

$$
E_{\mathrm{tot}}=\sum_{i} F_{i}\left(\rho_{i}\right)+\frac{1}{2} \sum_{i \neq j} \Phi_{i j}\left(R_{i j}\right)
$$

where $E_{\text {tot }}$ is the total energy of the atomic system, $\rho_{i}$ is the total host electron on the atom $i, R_{i j}$ is the distance between atom $i$ and atom $j, \Phi_{i j}$ is the pair inter-atomic potential, and $F_{i}$ is the embedding energy of the atom $i$. The constants of the EAM potential were obtained for $\mathrm{Ni}$ and $\mathrm{Al}$ by Pun and Mishin [24]. The interaction between the die-walls and the atoms of nano-crystalline particles are characterized by the Lennard-Jones inter-atomic potential. In order to alleviate the effect of compaction velocity, the top-punch movement is assumed with the speed of $0.4 \AA /$ picosec in the vertical direction. The compaction process is followed until all voids between nano-particles are vanished and the full-dense condition is achieved. The compaction simulation is performed under the canonical ensemble in which the temperature of system is preserved nearly constant. To manifest the influence of system temperature on the forming process, all numerical simulations are performed in two distinct values of temperature, i.e. 300 and $600 \mathrm{~K}$. To accomplish the numerical simulations, the open-source LAMMPS software is utilized [25].

In order to trace the distribution of dislocation in nano-particles, the parameter of centro-symmetry is computed over the component at different stages of the compaction process. This parameter is defined as [26]

$$
C S_{i}=\sum_{j=1}^{N / 2}\left|\mathbf{R}_{i j}+\mathbf{R}_{i(j+N / 2)}\right|^{2}
$$

in which $C S_{i}$ is the centro-symmetry parameter for the atom $i, N$ is the number of $i^{\text {th }}$ atom neighbors, and $\mathbf{R}_{i j}$ is the vector of atom $i$ to atom $j$. This parameter is approximately zero for atoms in the perfect F.C.C structure and has a positive value for the rest of atoms.

\section{Numerical simulation results}

In the process of powder forming, the nano-particles present the severe nonlinear deformations; so the molecular dynamics analysis is employed to model this nonlinear behavior. Despite the use of parallel processing technique, the maximum number of atoms is limited to 384000 atoms at each specimen due computational costs, which are placed in 64 nano-particles with the diameter of $5 \mathrm{~nm}$. As mentioned earlier, during the compaction process of nano-particles, several parameters, such as the temperature, number of nano-particles, the type of nano- powder, size of nano-particles, arrangement of different nano-particles and etc can have considerable influence in the mechanical properties of compacted component. On the other hand, in order to investigate the effect of each parameter given above, several numerical simulations should be performed. In this study, numerical simulations are performed employing two metallic nano-powders, i.e. the nickel and aluminum nano-particles, at different temperatures, various mixing ratios, and different number of nano-particles.

(a)

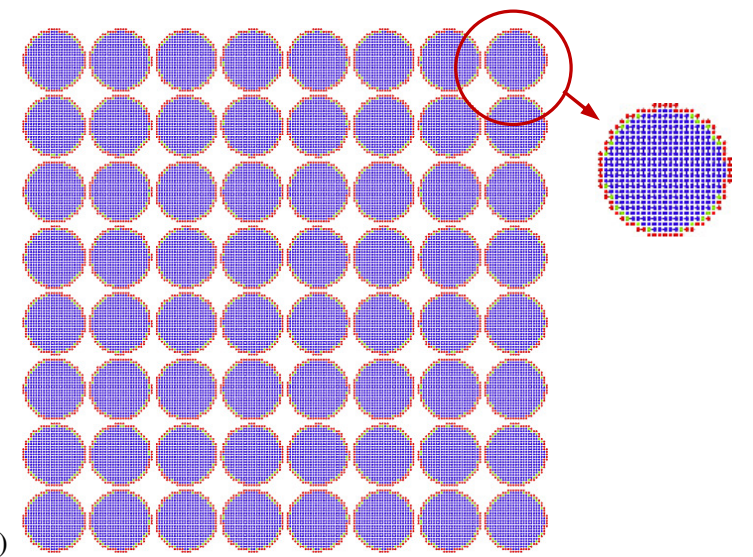

(b)

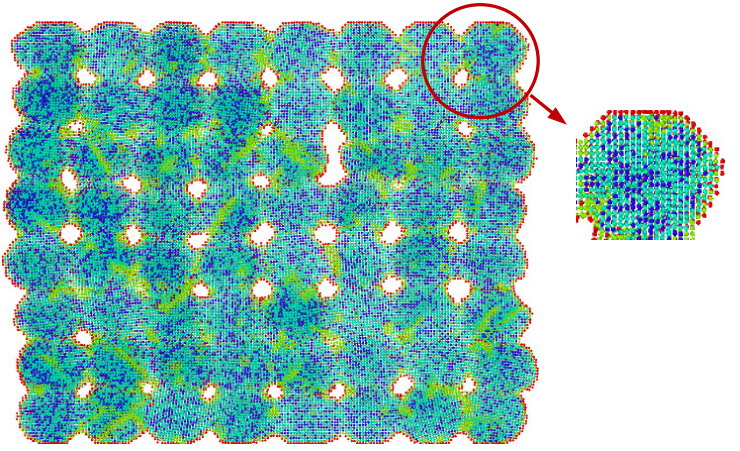

(c)

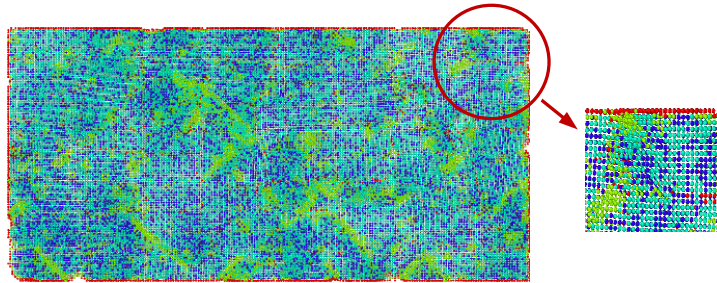

(d)

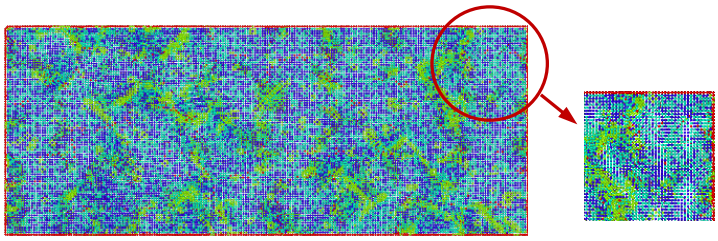

Figure 2. The snapshots of 64 aluminum nano-particles at different stages of compaction process in the temperature of $300 \mathrm{~K}$; (a) initial configuration, (b) $47 \%$, (c) $68 \%$ and, (d) $83 \%$ of relative density. The colors of atoms are displayed according to the normalized centro-symmetry parameter, in which the bold blue is atoms of the perfect F.C.C structure, the pale blue is atoms of partial dislocations in F.C.C structure, the green is atoms of stacking fault, and the red color is atoms of the surface 
In order to track the densification behavior of nanoparticles during the compaction process, the snapshots of deformed configurations are illustrated in Figure 2 at different levels of powder die-pressing for aluminum nano-particles. Obviously, by increasing the top punch movement, the nano-particles stick together due to their surface tension, and deform in a way that the voids between nano-particles reduce gradually until the nanoparticles form into the shape of the die. In this figure, the colors of atoms are presented according to the normalized centro-symmetry parameter computed with respect to the square of lattice constant for $\mathrm{Al}$ nano-particles at different stages of compaction process. In view of the aluminum crystallography, the normalized centro-symmetry value is zero for atoms of the perfect F.C.C structure displayed by the bold blue, however for atoms of partial dislocations in the F.C.C structure, it is almost between 0.03 and 0.18 (pale blue), for atoms of the stacking faults it is between 0.18 and 0.96 (green color), and for atoms of the surface it is more than 0.96 (red color) [27]. Obviously, the distribution of dislocations can be seen in this figure at different levels of die-forming process. The presence of dislocations clearly demonstrates the plastic behavior of nano-particles through the densification process.

In order to quantitatively demonstrate the nonlinear behavior of nano-particles during the forming process, the evolutions of the compaction pressure, relative density, the mean-stress of atoms in $y$-direction, and the strain of nano-particles are computed through the compaction process for each top punch movement of $0.2 \mathrm{~nm}$, and the results are plotted in the form of the relative density - pressure and stress-strain graphs. In Figures 3 and 4, the evolutions of relative density versus pressure and stress versus strain are plotted for a set of nine specimens, including the 4, 16, and 64 nanoparticles of the pure $\mathrm{Al}$, pure $\mathrm{Ni}$, and mixed $\mathrm{Al} / \mathrm{Ni}$ with mixing ratio of $50 \% \mathrm{Al}-50 \% \mathrm{Ni}$ at the temperature of $300 \mathrm{~K}$. It can be observed that for the relative density less than 75 percents, the graphs of relative density with 4,16 and 64 nano-particles are almost identical. In fact, up to 75 percents of the relative density, the difference in the number of nano-particles have no effect on the values of density. The reason of this phenomenon can be revealed from the corresponding stress-strain curves, as shown in Figure 4. Obviously, up to 75 percents of the relative density, the values of mean-stress in $y$-direction are approximately zero. It indicates that in this phase of forming process, the nano-particles do not experience a considerable deformation, and the compaction process is performed mainly by rearranging the nano-particles and decreasing the voids in the component. Evidently after this phase of forming process, the values of mean-stress of component develop rapidly and the densification curves corresponding to compaction of 4,16 and 64 nano-particles differ from each other. Obviously, in the last phase of forming process when the material becomes harden, the compaction pressure and the mean-stress value of compacted component increase as the number of nano-particles increases. Clearly, increasing the number of nano-particles results in a considerable discrepancy in the densification behavior corresponding to compaction of 4 and 16 nano-particles, while the graphs obtained from the compaction of 16 and 64 nano-particles represent a slight difference. Thus, it can be concluded that an appropriate number of 16 and/or 64 nano-particles results in a desired solution for the evolutions of relative density versus pressure and stress versus strain. In this study, the 16 nano-particles are used efficiently to capture the densification behavior of the pure $\mathrm{Al}$, pure $\mathrm{Ni}$, and mixed $\mathrm{Al} / \mathrm{Ni}$ with various mixing ratios at the temperature of $300 \mathrm{~K}$. Moreover, as it can be expected from Figures 3 and 4, the compaction pressure and the mean-stress value of the nickel nano-powders are clearly greater than those values of the aluminum nano-powders. In addition, the graphs of mixed $\mathrm{Al} / \mathrm{Ni}$ with mixing ratio of $50 \% \mathrm{Al}-50 \% \mathrm{Ni}$ are obtained in the region between the graphs of pure $\mathrm{Al}$ and pure $\mathrm{Ni}$ nano-particles.

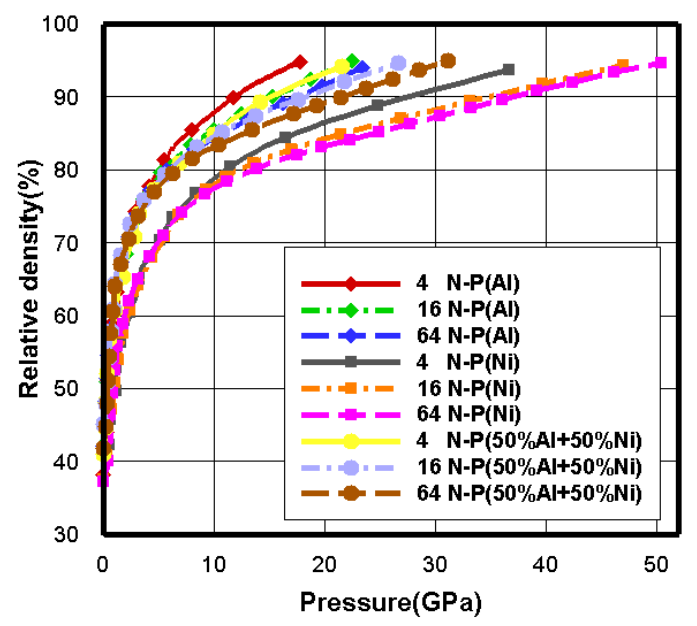

Figure 3. The variations of the relative density with pressure of the pure $\mathrm{Al}$, pure $\mathrm{Ni}$, and mixed $50 \% \mathrm{Al}-50 \% \mathrm{Ni}$ in specimens containing 4, 16 and 64 nano-particles at temperature of $300 \mathrm{~K}$

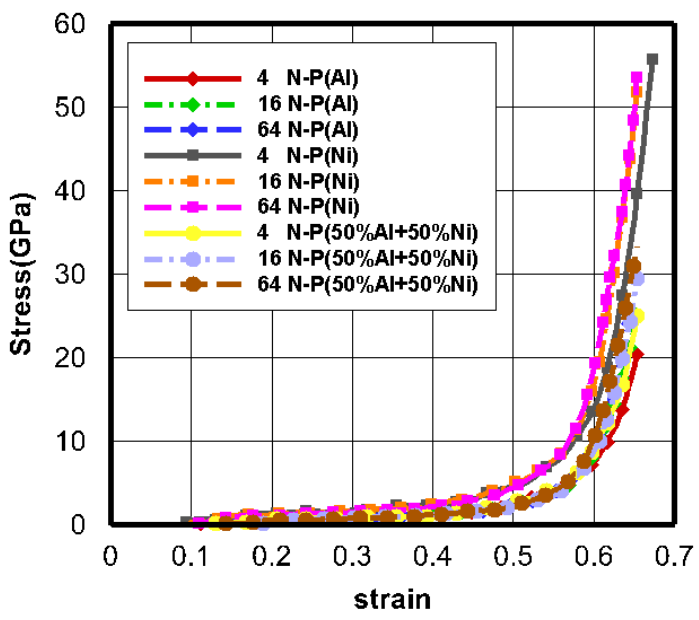

Figure 4. The stress - strain curves of the pure $\mathrm{Al}$, pure $\mathrm{Ni}$, and mixed $50 \% \mathrm{Al}-50 \% \mathrm{Ni}$ in specimens containing 4, 16 and 64 nano-particles at temperature of $300 \mathrm{~K}$ 


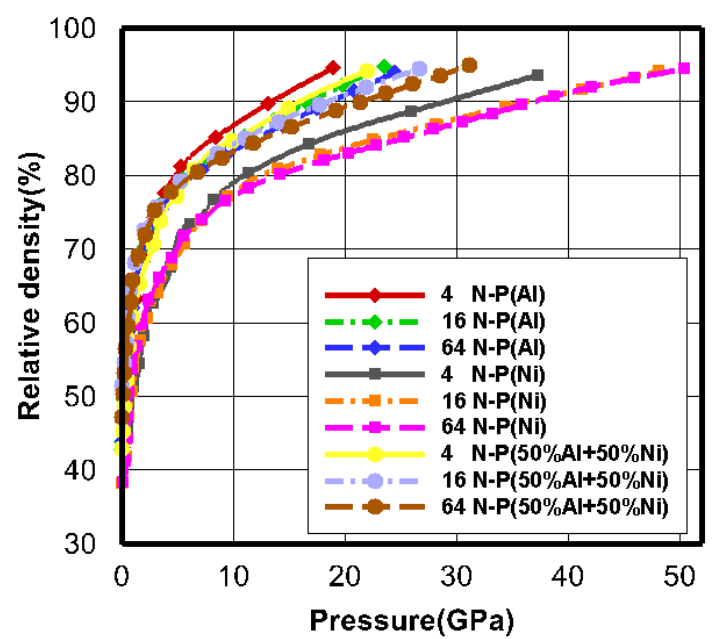

Figure 5. The variations of the relative density with pressure of the pure $\mathrm{Al}$, pure $\mathrm{Ni}$, and mixed $50 \% \mathrm{Al}-50 \% \mathrm{Ni}$ in specimens containing 4, 16 and 64 nano-particles at temperature of $600 \mathrm{~K}$

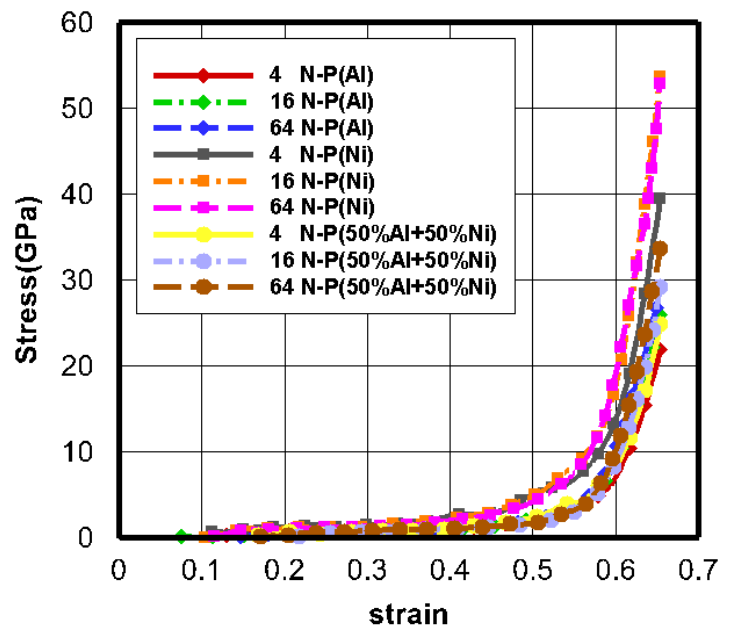

Figure 6. The stress - strain curves of the pure $\mathrm{Al}$, pure $\mathrm{Ni}$, and mixed $50 \% \mathrm{Al}-50 \% \mathrm{Ni}$ in specimens containing 4,16 and 64 nano-particles at temperature of $600 \mathrm{~K}$

In Figures 5 and 6, the variations of relative density with pressure as well as the evolutions of stress versus strain are plotted at the temperature of $600 \mathrm{~K}$ for different cases of pure $\mathrm{Al}$, pure $\mathrm{Ni}$, and mixed $\mathrm{Al} / \mathrm{Ni}$ with mixing ratio of $50 \% \mathrm{Al}-50 \% \mathrm{Ni}$. A comparison between the graphs plotted in these figures for the temperature of $600 \mathrm{~K}$ and those reported in Figures 3 and 4 for the temperature of $300 \mathrm{~K}$ reveals that the thermal compaction process affects the densification behavior of nanopowders. Basically, the trends of stress-strain curves as well as the relative density - pressure graphs are similar for the two temperatures of 300 and $600 \mathrm{~K}$, however, the temperature of the specimen moderately affects the values of compaction pressure and the mean-stress of the component. Obviously, by increasing the temperature, the velocity and the thermal vibration of the atoms increase in the component, which result in an increase of the interatomic forces and the atomistic stresses.
Accordingly, it can be deduced from the graphs of relative density versus pressure and stress versus strain obtained from molecular dynamics analyses that the compaction pressure and the mean-stress of the atoms increase during the forming process of nano-powders by increasing the temperature of the system. Since there are two different metallic nano-powders, i.e. the nickel and aluminum nano-particles, proposed in the numerical simulations, the effect of temperature is not identical on the densification behavior of various specimens. As can be observed from Figures 3-6, the specimens containing the aluminum nano-powders are more sensitive to the temperature in comparison with the specimens containing nickel nano-powders. On the other hand, the nickel nanoparticles display more resistant against the increasing of temperature in comparison with the aluminum nanoparticles during the compaction process.

In order to investigate the densification behavior of various combinations of $\mathrm{Ni}$ and $\mathrm{Al}$ nano-particles during the powder forming process, numerical simulations are performed for five mixing ratios, i.e. the pure $\mathrm{Al}$, pure $\mathrm{Ni}$, mixed $75 \% \mathrm{Al}-25 \% \mathrm{Ni}$, mixed $50 \% \mathrm{Al}-50 \% \mathrm{Ni}$, and mixed $25 \% \mathrm{Al}-75 \% \mathrm{Ni}$ nano-particles. In Figures 7 and 8 , the evolutions of relative density versus compaction pressure and the normal stress versus normal strain are plotted during the compaction simulations of 64 nano-particles at the temperature of $300 \mathrm{~K}$ for various mixing ratios. As can be seen from these figures, by increasing the percentage of nickel nano-particles, the value of compaction pressure as well as the mean-stress value of component increase, for which the maximum values of pressure and stress are obtained for the pure Ni nano-particles. It is obvious from Figure 7 that the mixed $\mathrm{Al} / \mathrm{Ni}$ with higher percentage of aluminum has a tendency to the pure $\mathrm{Al}$ curve, in a way that the difference between the curve of pure $\mathrm{Al}$ and that of mixed $75 \% \mathrm{Al}-25 \% \mathrm{Ni}$ nano-particles are negligible. In contrast, there is a remarkable gap between the graph obtained from the mixed $25 \% \mathrm{Al}-75 \% \mathrm{Ni}$ and that of the pure Ni nano-particles. This trend can be justified using the material properties of nickel and aluminum.

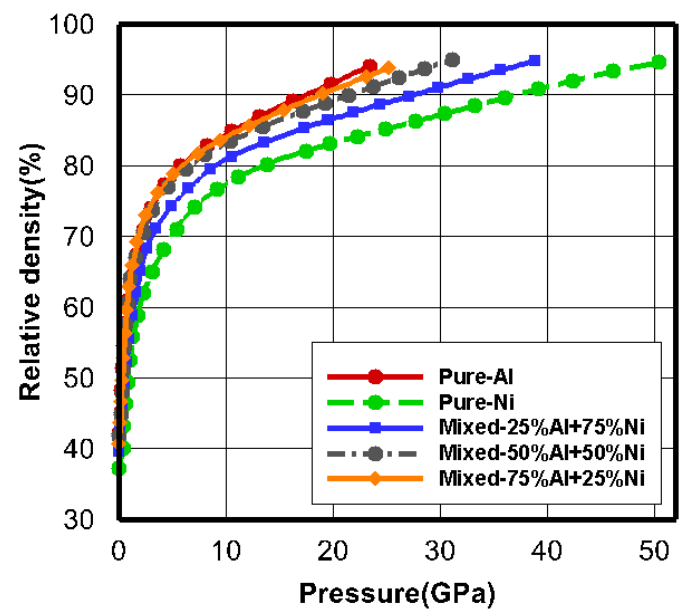

Figure 7. The variations of relative density with pressure of the pure $\mathrm{Al}$, pure $\mathrm{Ni}, 75 \% \mathrm{Al}-25 \% \mathrm{Ni}, 50 \% \mathrm{Al}-50 \% \mathrm{Ni}$, and $25 \% \mathrm{Al}-$ $75 \% \mathrm{Ni}$ in specimen of 64 nano-particles at temperature of $300 \mathrm{~K}$ 


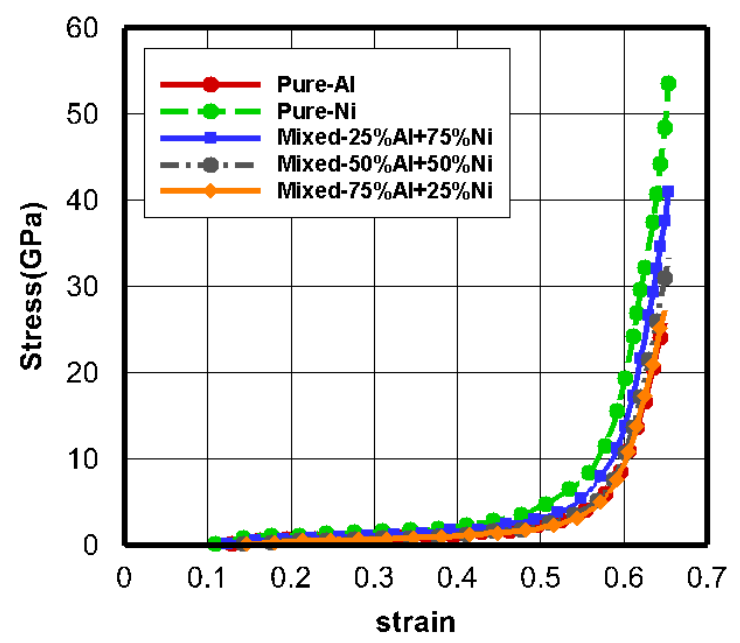

Figure 8. The stress - strain curves of the pure $\mathrm{Al}$, pure $\mathrm{Ni}$, mixed $75 \% \mathrm{Al}-25 \% \mathrm{Ni}, 50 \% \mathrm{Al}-50 \% \mathrm{Ni}$, and $25 \% \mathrm{Al}-75 \% \mathrm{Ni}$ in specimen of 64 nano-particles at temperature of $300 \mathrm{~K}$

In view of the mechanical behavior, nickel has a greater stiffness in comparison with aluminum, and has a more resistance against the deformation. Hence, in the compaction of Ni/Al nano-particles, the deformation of aluminum nano-particles is dominant and as a result, the corresponding graph has a tendency to the pure $\mathrm{Al}$ curve.

In order to investigate the temperature effect during the compaction process of mixed $\mathrm{Ni} / \mathrm{Al}$ nano-particles, numerical simulations are performed at the temperature of $600 \mathrm{~K}$. In Figures 9 and 10, the variations of relative density with compaction pressure are plotted together with the evolutions of normal stress versus normal strain for various mixing ratios of the pure $\mathrm{Al}$ and pure $\mathrm{Ni}$, mixed $75 \% \mathrm{Al}-25 \% \mathrm{Ni}$, mixed $50 \% \mathrm{Al}-50 \% \mathrm{Ni}$, and mixed $25 \% \mathrm{Al}-75 \% \mathrm{Ni}$ nano-particles. It can be observed from various combinations of $\mathrm{Ni} / \mathrm{Al}$ nano-particles that by increasing the temperature of the system, the values of stress and pressure increase during the compaction process. Note that although the temperature has different effects on the behavior of nickel and aluminum, it can be seen from Figures 9 and 10 that the influence of temperature is more important in the cases of pure $\mathrm{Al}$ and mixed $75 \% \mathrm{Al}-25 \% \mathrm{Ni}$, and the increase of temperature does not make a considerable effect on the stress-strain and relative density - pressure graphs of the remaining mixed Ni/Al combinations. In Figure 11, the contours of normal stress are presented for various mixing ratios of 64 nano-particles at the final stage of compaction process in the temperature of $300 \mathrm{~K}$. Obviously, the value of normal stress increases as the percentage of nickel nanoparticles increases in the component for which the maximum stress value can be observed for the pure $\mathrm{Ni}$ nano-particles. Finally, the distributions of dislocations are shown in Figure 12 for various mixing ratios of 64 nano-particles at the relative density of $85 \%$. It can be seen that the number of dislocations increases as the percentage of nickel nano-particles increases for which the maximum number of dislocations is obtained for the pure Ni nano-particles.

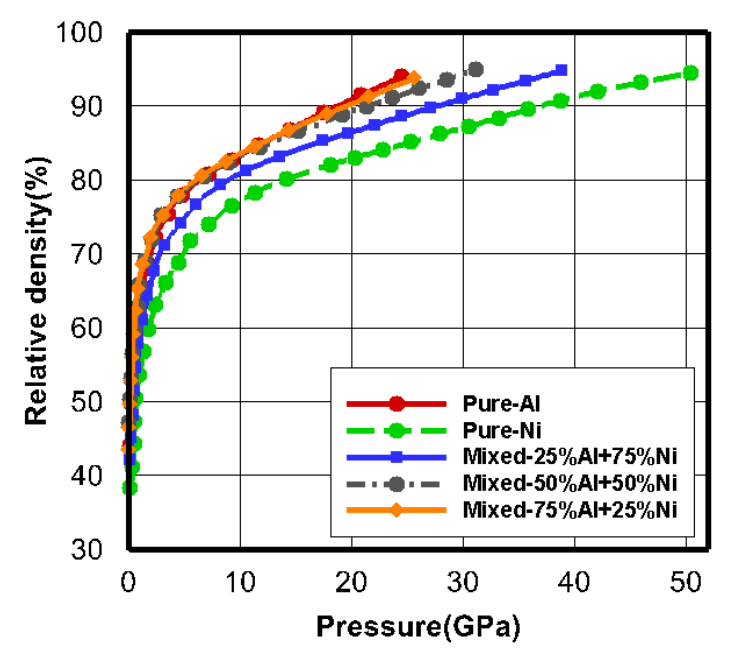

Figure 9. The variations of the relative density with pressure of the pure $\mathrm{Al}$, pure $\mathrm{Ni}$, mixed $75 \% \mathrm{Al}-25 \% \mathrm{Ni}$, mixed $50 \% \mathrm{Al}-$ $50 \% \mathrm{Ni}$, and mixed $25 \% \mathrm{Al}-75 \% \mathrm{Ni}$ in the specimen of 64 nanoparticles at the temperature of $600 \mathrm{~K}$

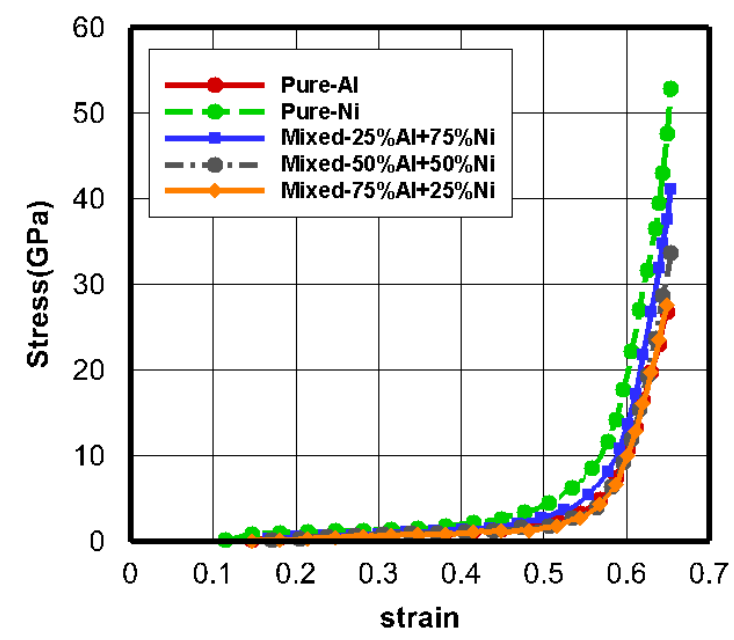

Figure 10. The stress - strain curves of the pure $\mathrm{Al}$, pure $\mathrm{Ni}$, mixed $75 \% \mathrm{Al}-25 \% \mathrm{Ni}$, mixed $50 \% \mathrm{Al}-50 \% \mathrm{Ni}$, and mixed $25 \% \mathrm{Al}-75 \% \mathrm{Ni}$ in the specimen of 64 nano-particles at the temperature of $600 \mathrm{~K}$

\section{Conclusion}

In the present paper, the three-dimensional compaction simulation of nano-crystalline metal powders was presented based on the molecular dynamics method. The EAM pair-potential was used to model the forming process of nano-particles at different temperatures, various number of nano-particles, and different mixing ratios of nickel and aluminum. The Lennard-Jones interatomic potential was utilized to model the interaction between the atoms of nano-particles and die-walls. The forming process was model in uniaxial compression, and the compaction process was followed until the full-dense condition was attained at the constant temperature. 
(a)

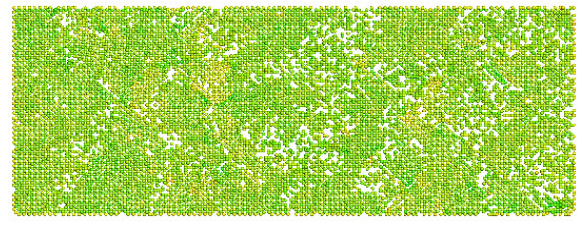

(b)

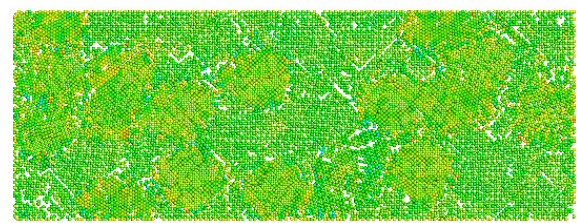

(c)

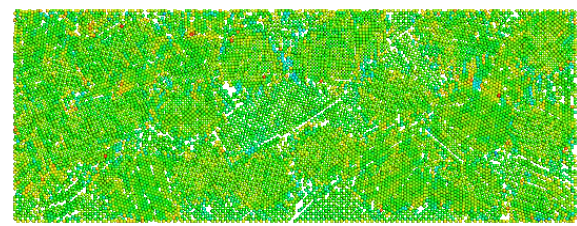

(d)

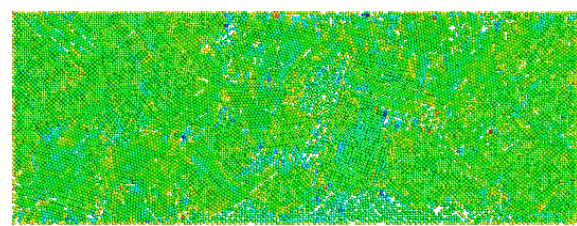

(e)

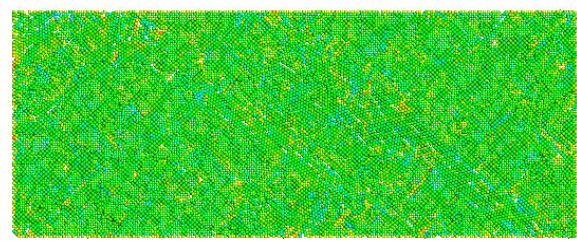

$-80-70-60-50-40-30-20-10 \quad 0 \quad 1020$

Figure 11. The contours of normal stress (GPa) for 64 nanoparticles in the temperature of $300 \mathrm{~K}$ at the final stage of compaction process; (a) pure $\mathrm{Al}$, (b) mixed $75 \% \mathrm{Al}-25 \% \mathrm{Ni}$, (c) mixed $50 \% \mathrm{Al}-50 \% \mathrm{Ni}$, (d) mixed $25 \% \mathrm{Al}-75 \% \mathrm{Ni}$, (e) pure $\mathrm{Ni}$

The numerical simulations were performed on a set of specimens with different number of particles containing the pure $\mathrm{Ni}$, pure $\mathrm{Al}$, and mixed $\mathrm{Ni} / \mathrm{Al}$ nano-powders under the uniaxial compression. In order to study the influence of various parameters in the compaction process of nano-powders, the numerical simulations were carried out with different number of nano-particles, various temperatures, and different mixing ratios of $\mathrm{Ni} / \mathrm{Al}$. The distribution of dislocations was traced by presenting the contours of centro-symmetry parameter at different levels of the compaction process; it was shown that the voids between the nano-particles reduce, the material becomes harden, and the plasticity behavior of nano-particles plays an important role in the forming process. It was shown that increasing the number of nano-particles results in a significant discrepancy in the densification behavior corresponding to compaction of 4 and 16 nano-particles, however, the results have a slight difference in the compaction of 16 and 64 nano-particles. (a)

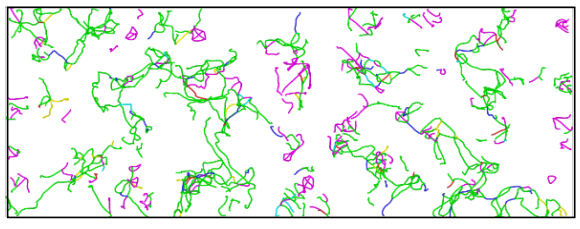

(b)

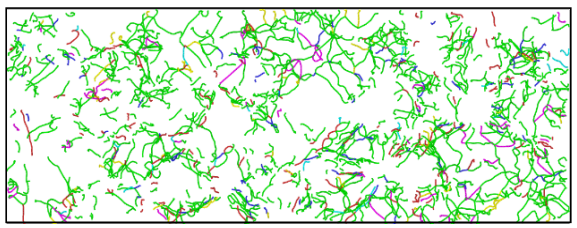

(c)

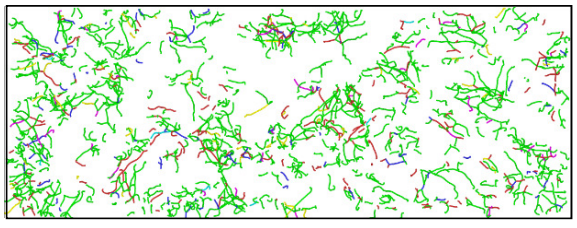

(d)

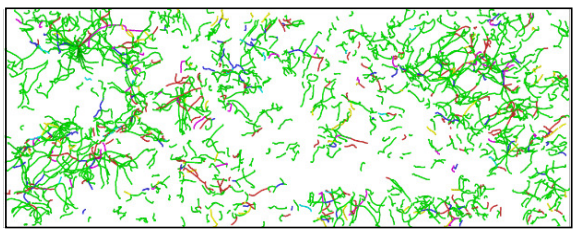

(e)

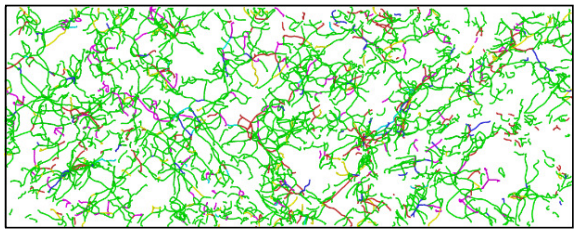

Figure 12. The distributions of dislocations for 64 nanoparticles in the temperature of $300 \mathrm{~K}$ at the powder compaction of $85 \%$; (a) pure $\mathrm{Al}$, (b) mixed $75 \% \mathrm{Al}-25 \% \mathrm{Ni}$, (c) mixed $50 \% \mathrm{Al}-50 \% \mathrm{Ni},(\mathrm{d})$ mixed $25 \% \mathrm{Al}-75 \% \mathrm{Ni},(\mathrm{e})$ pure $\mathrm{Ni}$

It has been concluded that an appropriate number of 16 nano-particles can be used to obtain a desired solution for the evolutions of relative density versus pressure and stress versus strain. Furthermore, it was shown from molecular dynamics analyses that by increasing the temperature of the system the compaction pressure and the mean-stress of the atoms increase during the forming process of nano-powders. It was observed that the nickel nano-particles present more resistant against the increase of temperature comparing to the aluminum nano-particles during the compaction process. In addition, it was shown from the evolutions of compaction pressure and the mean-stress of compacted component that the mixed Al/Ni nano-particles with higher percentage of aluminum has a tendency to the pure Al behavior, in which the difference between the curve of pure $\mathrm{Al}$ and that of mixed $75 \% \mathrm{Al}-25 \% \mathrm{Ni}$ are negligible. In fact, it was observed that in the compaction of mixed $\mathrm{Ni} / \mathrm{Al}$ nano-particles, the deformation of aluminum nano-particles is dominant and as a result, the corresponding result has a tendency to the pure Al behavior. The numerical simulations clearly 
demonstrated that the molecular dynamics method is capable to model the compaction process of nanocrystalline metal powders.

\section{References}

1. A.R. Khoei, Computational Plasticity in Powder Forming Process, (Elsevier 2005)

2. J.H. Cho, K.T. Kim, Int. J. Mech. Sciences 43, 921 (2001)

3. R.S. Ransing, D.T. Gethin, A.R. Khoei, P. Mosbah, R.W. Lewis, Mater. Design 21, 263 (2000)

4. P. Redanz, N.A. Fleck, Acta Mater. 49, 4325 (2001)

5. J.F. Jerier, B. Hathong, V. Richefeu, B. Chareyre, D. Imbault, F.V. Donze, P. Doremus, Powder Tech. 208, 537 (2011)

6. A.R. Khoei, S.O.R. Biabanaki, S.M. Parvaneh, Appl. Math. Model. 37, 443 (2013)

7. A.R. Khoei, A.R. Azami, Int. J. Mech. Sciences 47, 94 (2005)

8. A.R. Khoei, H. DorMohammadi, Comp. Mater. Sci. 41, 1 (2007)

9. T. Pu, Annu. Rep. Prog. Chem. Sect. C: Phys. Chem. 104, 142 (2008)

10. G.S. Boltachev, K.E. Lukyashin, V.A. Shitov, N.B. Volkov, Phys. Rev. E 88, 012209 (2013)

11. G.S. Boltachev, N.B. Volkov, Technic. Phys. Let. 36, 823 (2010)
12. R. Suryanarayanan, S.M.L. Sastry, Acta Mater. 47, 3079 (1999)

13. A. Balakrishnan, P. Pizette, C.L. Martin, AIP Conf. Proc. 1145, 105 (2009)

14. B.J. Henz, T. Hawa, M. Zachariah, J. Appl. Phys. 105, 124310 (2009)

15. B.J. Henz, T. Hawa, M. Zachariah, Molecul. Simul. 35, 804 (2009)

16. Y.W. Zhang, P. Liu, C. Lu, Acta Mater. 52, 5105 (2004)

17. T.W. Stone, M.F. Horstemeyer, Y. Hammi, P.M. Gullett, Acta Mater. 56, 3577 (2008)

18. S.P. Kiselev, J. Appl. Mech. Technic. Phys. 48, 412 (2007)

19. S.P. Kiselev, J. Appl. Mech. Technic. Phys. 49, 712 (2008)

20. D.L. Olmsted, L.G. Hector, W.A. Curtin, R.J. Clifton, Model. Simul. Mat. Sci. Eng. 13, 371 (2005)

21. C. Zhang, H. Wang, Y. Qiu, Eng. 3, 227 (2011)

22. M.S. Daw, M.I. Baskes, Phys. Rev. Let. 50, 1285 (1983)

23. M.S. Daw, M.I. Baskes, Phys. Rev. B 29, 6443 (1984)

24. G.P. Pun, Y. Mishin, Philosoph. Mag. 89, 3245 (2009)

25. LAMMPS Molecular Dynamics Simulator Code. http://lammps.sandia.gov

26. C.L. Kelchner, S.J. Plimpton, J.C. Hamilton, Phys. Rev. B 58, 11085 (1998)

27. B. Tang, R. Yang, Chin. J. Phys. 53, 120802 (2015) 